\title{
Characterization of Tandem
}

\section{Organic Solar Cells}

To the Editor - The tandem solar cell approach is a promising concept for organic photovoltaics (OPV). However, efficiency determination or in general electrical characterization of multijunction solar cells is challenging. We performed a literature survey of tandem OPV publications from the period 2009 to September 2014 and came to the alarming conclusion that $96 \%$ of the published efficiencies were not measured according to the relevant standards (see Table 1). Even most of the publications claiming to report record efficiencies characterize their devices insufficiently or even wrongly. The main reason for this malpractice is probably that researchers lack access to adequate experimental equipment for correctly calculating spectral mismatches. The absence of matched reference cells for OPV makes this even more challenging. Authors treating tandem organic solar cells exactly like single solar cells even suggest being not measuring tandem solar cells.

For the sake of reliability of the whole OPV community, especially when considering the commercial potential of this technology, correct and comparable characterization of devices should be aware of the existing standards for

emphasized much more in future. ${ }^{5}$ Here, we attempt to draw attention to this problem by giving specific practical instructions for a correct measurement of tandem organic solar cells. The in-depth analysis underlying these instructions can be found in the Supplementary Information. There, we summarize the measurement procedures as requested by the standards and associated literature in the first part. In the second part of the Supplementary Information, the different characterization methods for organic tandem solar cells are applied to an example device. Based on these experiments general rules to achieve correct characterization results for tandem organic solar cells are formulated that are presented here.

Usually, the subcells of a tandem solar cell are connected in series and there is no separate electrical access to the subcells. Therefore, two main challenges exist: First, the measurement of the spectral response (SR) or external quantum efficiency (EQE ) - being essential for the spectral correction when using a sun simulator for JVmeasurements - is only possible with special measurement procedures ${ }^{1}$. Second, for the efficiency determination itself, a spectrally adjustable sun

\begin{tabular}{|l|c|c|}
\hline \multicolumn{1}{|c|}{$\begin{array}{c}\text { Quality of tandem organic solar cell } \\
\text { characterization }\end{array}$} & $\begin{array}{c}\text { number of } \\
\text { publications }\end{array}$ & percentage \\
\hline according to standard & $3^{2-4}$ & $4 \%$ \\
\hline $\begin{array}{l}E Q E \text { for the subcells shown (not only } \\
\text { dummy single cells) } \\
\text { No comment on mismatch factor } M \text { or } \\
M \text { not used for characterization }\end{array}$ & 33 & $45 \%$ \\
\hline $\begin{array}{l}\text { No } E Q E \text { for subcells shown } \\
\text { No comment on } M\end{array}$ & 37 & $51 \%$ \\
\hline
\end{tabular}

Table 1: Analysis of the publication practice of tandem organic solar cell efficiencies in selected publications in Web of Science. The analysis is mainly based on a search with the keywords "TITLE: (tandem AND (organic OR polymer) AND (solar cell or photovoltaic)) AND YEAR PUBLISHED: (20092014)". Review papers and papers where the tandem organic solar cell efficiency characterization is not in the focus of the work as well as papers only showing simulation results are not included. The total number of analyzed papers is 73 . The full list of references can be found in the Supplementary Information. simulator is mandatory to achieve correct results ${ }^{1}$.

However, a measurement of tandem OPV cells according to the existing standards will only assure correct results when applying the standards with special care regarding the peculiarities of organic solar cells. The following four main challenges to be carefully considered when characterizing tandem organic solar cells have been identified.

Organic solar cells often suffer from lower fill factors compared to inorganic solar cells. Apart from the efficiency record cells of the last years with fill factors of $70 \ldots 80 \%$, tandem organic solar cells mostly have fill factors in the range of $50 . .70 \%$ which is much less than for typical inorganic tandem solar cells. (For a list of references see the Supplementary Information.) However, even a high fill factor of a tandem solar cell does not necessarily mean that both subcells have high fill factors, too ${ }^{6}$. If one of the subcells of a tandem solar cell suffers from a low fill factor, characterization is even more challenging and especially regarding the measurement of the spectral response, the appearance of measurement artifacts is likely. Correction methods for measuring artifacts ${ }^{7}$ require spectrally non-overlapping absorbers which is mostly not the case for OPV. Since reasons for low fill factors in OPV are manifold and cannot simply be attributed to high series or low shunt resistances its impact on characterization has to be considered with great care.

Other challenges for the characterization of tandem organic solar cells are distinct nonlinearities. The major issue is the nonlinear behavior of the $j_{s c}$ as a function of the irradiance. Although these nonlinearities are not specific for organic solar cells and do also occur for many inorganic solar cells, they are much more relevant for OPV cells, especially polymer based ones $^{8}$. 


\section{General rules for characterizing tandem organic solar cells}

1. Estimate the bias light conditions for the SR-measurement. Select the spectrum of the bias light according to the absorption spectrum of the absorber materials. If both subcells comprise identical absorber materials, proceed as given in reference ${ }^{10}$ where detailed optical simulations are carried out to decide for the bias light spectrum. Select the intensity of the bias light such that always the SR of the intended subcell is being measured.

2. Estimate the bias voltage conditions for the SR-measurement based on the expected voltages of the subcells. As a first approximation, the open circuit voltages $V_{o c}$ of single solar cells incorporating the same absorber system can be used.

3. Measure the SR of both subcells according to standard ASTM E2236 using chopped monochromatic light in conjunction with lock-in technique applying the above determined bias voltage and bias light conditions. Additionally, measure the SR without bias light and check if it follows the lower envelope of the spectra with bias light.

4. Based on the results of the SR-measurement, determine the intensities of the two sources of a spectrally adjustable sun simulator such that both subcells are mismatch corrected. Use either the iterative procedure of standard ASTM E2236 or one of the methods described in references ${ }^{11-12}$. Measure the JV-characteristics of the solar cell and determine the efficiency.

Since the effective solar cell area has a crucial influence on the efficiency, put emphasis on its determination.

Additionally to the presented procedure, we strongly advise that in publications, reporting on tandem organic solar cell efficiencies, at least the following information about the characterization procedures and setups should be stated to ensure reproducibility and comparability as well as an estimation of the accuracy of the published results:

- SR- / EQE-measurement

- Setup description and aperture size

- Bias voltage used for each subcell

- Bias illumination intensity and used light sources (the spectra should be included in the Supplementary Information)

- JV-measurement

- Setup description and aperture size

- Description of the solar simulator (the spectra should be included in the Supplementary Information)

- In case of a single source sun simulator: Mismatch factor $M$ of both subcells under the used solar simulator and a detailed analysis of the potential deviation of the efficiency from the SRC-value.

On top of this, a so-called photoshunt effect has been observed for organic solar cells. ${ }^{9}$

Finally, organic tandem solar cells often have non-complementary absorbers. The selection of parameters for spectral response measurement should therefore be carried out very carefully.

Most of the peculiarities of organic tandem solar cells do not necessitate modifications of the measurement procedures as given by the standards, but requires special care for certain steps of the measurement procedures. Based on the analysis presented in the Supplementary Information we present practical advice how to characterize tandem organic solar cells to achieve results considering the described peculiarities, conforming to the measurement standards and being as accurate and reproducible as possible (see box "General rules for characterizing tandem organic solar cells"). The Supplementary Information give additional optional steps to this procedure that can improve validity and accuracy, but are not considered to be mandatory.

\section{References}

1. ASTM E2236-10, ASTM International, West Consohocken, PA, 2010, www.astm.org

2. You, J. et al. Nat. Commun. 4, 1446 (2013)

3. Riede, M. et al. Adv. Funct. Mater. 21

3019-3028 (2011)

4. Dou, L. et al. Nat. Photonics 6, 180-185 (2012)

5. Zimmermann, E. et al. Nat. Photonics 8 ,

669-672 (2014).

6. Ameri, T., Dennler, G., Lungenschmied, C. \& Brabec,

C.J. Energy Environ. Sci. 2, 347-363 (2009)

7. Siefer, G., Baur, C. \& Bett, A. Proceedings of the 35th IEEE Photovoltaic Specialists Conference, Honolulu, HI, USA 704 -707 (2010)

8. Koster, L.J.A., Kemerink, M., Wienk, M.M., Maturova, K. \& Janssen, R.A.J. Adv. Mater. 23, 1670 (2011)

9. Tress, W., Leo, K. \& Riede, M. Phys. Status Solidi RRL 7, 401-405 (2013)

10. Timmreck, R., Leo, K. \& Riede, M. Prog. Photovolt: Res. Appl. published online (2014)

11. Meusel, M., Adelhelm R., Dimroth, F.,

Bett A.W. \& Warta, W. Prog. Photovolt: Res. Appl. 10, 243-255 (2002)

12. Moriarty, T. Jablonski, J. \& Emery, K. Proceedings of $38^{\text {th }}$ IEEE Photovoltaics Specialists Conference, Austin, Texas, USA 001291-001295 (2012)

\author{
Ronny Timmreck ${ }^{1}$, Toni Meyer ${ }^{1}$, Jan \\ Gilot $^{2}$, Holger Seifert ${ }^{3}$, Toni Mueller, \\ Alice Furlan ${ }^{5}$,Martijn M. Wienk ${ }^{5}$, David \\ Wynands ${ }^{1,6}$, Jochen Hohl-Ebinger ${ }^{3}$, \\ Wilhelm Warta ${ }^{3}$, René A.J. Janssen ${ }^{5 * *}$, \\ Moritz Riede ${ }^{1,7}$, Karl Leo $^{1^{*}}$ \\ ${ }^{1}$ Institut für Angewandte Photophysik, Technische \\ Universität Dresden (TUD), 01062 Dresden, \\ Germany \\ ${ }^{2}$ Holst Centre, High Tech Campus 31, 5656 AE, \\ Eindhoven, The Netherlands \\ ${ }^{3}$ Fraunhofer Institute for Solar Energy Systems \\ (ISE), Heidenhofstr. 2, 79110 Freiburg, Germany \\ ${ }^{4}$ Heliatek GmbH, Treidlerstr. 3, 01139 Dresden, \\ Germany \\ ${ }^{5}$ Molecular Materials and Nanosystems, \\ Eindhoven University of Technology (TUe), 5600 \\ MB Eindhoven, Netherlands \\ ${ }^{6}$ Present address: Fraunhofer COMEDD, Maria- \\ Reiche-Straße 2, 01109 Dresden, Germany \\ ${ }^{7}$ Present address: Clarendon Laboratory, Physics \\ Department, University of Oxford, Parks Road, \\ Oxford OX1 3PU England, UK \\ *e-mail: leo@iapp.de \\ **e-mail: r.a.j.janssen@tue.nl
}

